\title{
Current strategies for osteochondral regeneration: from stem cells to pre-clinical approaches Márcia T Rodrigues ${ }^{1,2}$, Manuela E Gomes ${ }^{1,2}$ and Rui L Reis ${ }^{1,2}$
}

\begin{abstract}
Damaged cartilage tissue has no functional replacement alternatives and current therapies for bone injury treatment are far from being the ideal solutions emphasizing an urgent need for alternative therapeutic approaches for osteochondral (OC) regeneration. The tissue engineering field provides new possibilities for therapeutics and regeneration in rheumatology and orthopaedics, holding the potential for improving the quality of life of millions of patients by exploring new strategies towards the development of biological substitutes to maintain, repair and improve OC tissue function. Numerous studies have focused on the development of distinct tissue engineering strategies that could result in promising solutions for this delicate interface. In order to outperform currently used methods, novel tissue engineering approaches propose, for example, the design of multi-layered scaffolds, the use of stem cells, bioreactors or the combination of clinical techniques.
\end{abstract}

\author{
Addresses \\ ${ }^{1}$ 3B's Research Group - Biomaterials, Biodegradables and \\ Biomimetics, Univ. of Minho, Headquarters of the European Institute of \\ Excellence on Tissue Engineering and Regenerative Medicine, AvePark, \\ 4806-909 Taipas, Guimarães, Portugal \\ ${ }^{2}$ IBB - Institute for Biotechnology and Bioengineering, PT Government \\ Associated Laboratory, Guimarães, Portugal \\ Corresponding author: Reis, Rui L (rgreis@dep.uminho.pt) \\ Current Opinion in Biotechnology 2011, 22:1-8 \\ This review comes from a themed issue on \\ Tissue, cell and pathway engineering \\ Edited by Uwe T. Bornscheuer and Ali Khademhosseini \\ 0958-1669/\$ - see front matter \\ Published by Elsevier Ltd. \\ DOI 10.1016/j.copbio.2011.04.006
}

\section{Introduction}

Osteochondral (OC) interfaces are part of the joint, being a specialized and integrated structure consisting of multiple connective tissue elements, including muscles, tendons, ligaments, synovium, cartilage, and bone, organized to permit stability and movement of the human skeleton.

OC injuries can lead to joint malfunction and ultimately to the development of degenerative diseases such as osteoarthritis. With an increasing aging population, OA represents a significant socio-economical burden world- wide. Although several procedures are available on the clinical market, an ideal solution has yet to be found in order to fulfil all necessary requirements for a long-term successful regenerative approach.

This paper is aimed at reviewing distinct strategies aiming at a successful OC regeneration, involving cells, scaffolds, bioreactors or a combination of these elements. The rationale for currently used techniques as well as some promising studies in animal models will also be discussed in this review in order to highlight the state-ofthe-art in OC over the past few years (Figure 1).

One of the most challenging goals in bone and cartilage tissue engineering (TE) is the creation of an engineered OC interface to repair damaged areas. Similarly to the natural milieu, an engineered interface should distribute everyday mechanical stresses with low-friction load bearing, while interacting with different structural and biological needs in a stable environment. This is particularly more demanding and unique if one considers the distinctive requirements of bone and cartilage tissues as well as the several OC systems found in the human body, dependent on their location and functionality.

Several materials, shapes, stiffness and chemical compositions were described for bone [1-8] and cartilage scaffolds $\left[8-11,12^{\bullet}, 13-20,21^{\circ}\right]$, considering the relevance of scaffold architecture to sustain the mechanical stresses of the joint as well as to guide the cells into the desired phenotype, and promoting a complete integration of the OC system in order to restore tissue functionality.

The selection of cells also plays an important element in this delicate interface headed for engineered grafts. Several potential cell sources were successfully described for bone [22-26], and cartilage [17,22-27], which are likely to be useful for OC strategies [8].

The subsequent step towards the clinical application is the up-scale and custom made production of the OC implants to fit perfectly to the injured area and to provide the biological and structural needs required to restore tissue function. In order to automate and make the system cost-effective, several bioreactor models [28,29] were designed and have been showing promising results.

\section{Osteochondral defects (OCD)}

Most OC lesions or defects (OCD) and OC injuryassociated diseases lead to loss of integrity or stability 
2 Tissue, cell and pathway engineering

Figure 1

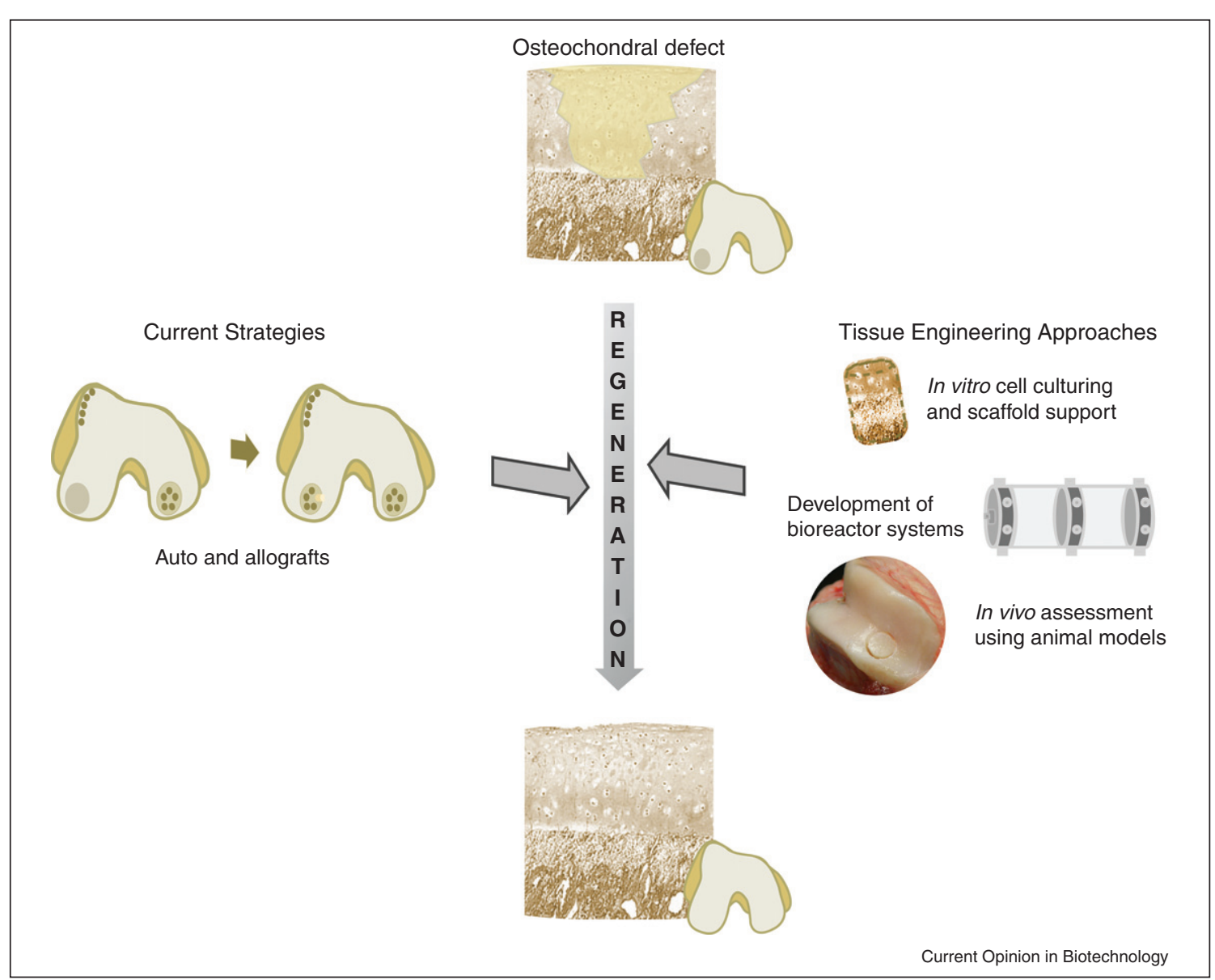

Clinical and tissue engineering strategies to promote the regeneration of osteochondral defects.

at the articular surface with resultant decrease range of motion of the involved joint, and, ultimately, premature osteoarthritis (OA) [30]. Although OCDs occur as a result of repetitive trauma within the joint, several factors, such as ischemia, genetics, abnormal vasculature, and metabolic disorders are associated with body processes leading to loss of cartilage [31] or to relevant changes in the architecture or composition of the bone [32]. Furthermore, joint healing is strongly dependent on age, as age is the strongest known risk factor for the development of OA [33] and depth of injury is also age associated [34]. Aged cartilage also induces changes in chondrocyte function and material properties, and responds differently to cytokines and growth factors [33].

The location of a particular defect [35] does influence repair response of the cartilage as well as the mechanical alignment of the joint [36]. OC lesions are identified most frequently in the femoral condyles [37], capitellum of the elbow [38], dome of the talus [30], and the dorsal surface of the patella [37].

\section{Weight bearing influence in biomechanics of the joint}

Homeostasis of articular cartilage depends on mechanical loads generated during daily activity. Some joint areas are particularly more affected by weight pressure than others, which may progress to a more degenerative and diffuse joint involvement that translates to the patient by causing pain, swelling, clicking, and instability. Ultimately, inappropriate joint loads are associated with focal stress and result in focal degeneration of cartilage, as that occurs in $\mathrm{OA}$, and increase the stress on subchondral bone. Changes in pressure and shear stress induced by joint movement may induce changes in matrix protein expression and in the release of nitric oxide associated with joint pathogenesis [39].

The stress may also vary throughout the cartilage on a joint surface, because loading is not completely uniform, leading to gradients in stress and pressure [40]. This effect is evident in most patients, where the surface of the joints does not conform perfectly under loading and may result in an increased risk for OA progression [33]. 


\section{Current treatments in clinical field}

Currently available treatments depend upon the size of the OC defect and the condition of the overlying cartilage. Using reparative surgery, cartilage treatments include arthroscopic debridement, abrasion arthroplasty, and microfracture. These procedures stimulate the body to heal the injury, mainly resulting in the formation of fibrocartilage [41]. Fibrocartilage is a scar tissue presenting diminished resilience, reduced stiffness, and poor wear characteristics when compared to hyaline cartilage. Thus, fibrocartilage is unlikely to withstand physiological loading and cannot guarantee to function successfully in long term. Nevertheless, other options are available with restorative surgery, namely, autografts recurring to mosaicoplasty procedures, allografts $[42,43]$ and biologic replacement using cultured autologous chondrocytes $[44,45]$. The biggest challenge with autografts is to achieve a final round shape that mimics the surface of the articular joints. Allograft procedure is similar to autografts [46] and mostly used after other surgeries have failed. It is not recommended for patients with OA, and the limited supply of donor tissue is a major problem of this practice.

Autologous chondrocyte transplantation/implantation [44] has also been described to help restoring the structural make-up of the articular cartilage. The intermediate and long-term functional and clinical results are promising, especially regarding the durability of the repair in human patients follow-up [45].

More recently [47], tissues from the covering of bone and cartilage are implanted into the lesion through periosteal and perichondral grafting to promote the repair and functionality of cartilage.

Despite the availability of procedures, all current treatment options inflict further tissue destruction before any therapeutic effect can be achieved.

\section{TE strategies to improve available treatments Cells to promote healing}

Despite current knowledge on OC field, the selection of a cell source to promote efficient OC regeneration is a major issue that must to be considered. Ideally, a cell source should enable insignificant donor morbidity or tissue scarcity, resurface joints with cartilage, have no limitations in the amounts available and be easy to maintain/expand in vitro, be readily available, have no issues of immunogenicity or disease transmission risks and be of low cost.

Tissue insufficient supply and morbidity, and host immune responses and disease transmission risks limit chondrocyte and osteoblast as ideal cells in OC strategies. Among adult stem cells, bone marrow mesenchymal stem cells (BMSCs) [15,16,19,20,22,48-51] and adiposederived stem cells (ASCs) $\left[9,12^{\bullet}, 26,48,50,52\right]$ are the most investigated. Nevertheless, some studies described a higher chondrogenic [50] and osteogenic [48] potential of BMSCs when compared to ASCs. The effectiveness of autologous BMSCs transplantation for the repair of fullthickness articular cartilage defects was assessed in patellae lesions of two human patients [53]. A similar approach was also considered to repair full thickness femoral condyle defect in an athlete, who had reattained his previous activity level and experienced neither pain nor other complications [27].

Other cell sources, including synovial tissue and periosteum-derived stem cells have also showed potential for osteogenic and chondrogenic differentiation [24,54]. Cells from synovial membrane are harvested with minimal complications at the donor site due to a high selfregenerative capability [24] of synovial tissue. The periosteum is a specialized fibrous tissue composed of fibroblast, osteoblast, and progenitor cells that may also be a possible cell source for OC TE based on its accessibility, rapid proliferation and differentiation potential [54]. Furthermore, after skeletal surgery procedures, periosteum is often used as a covering layer over tissue to stimulate local regeneration. Despite the potential, periosteum-derived cells should be more investigated for cellular therapies [55].

Umbilical cord stem cells (UCSCs) together with amniotic fluid derived stem cells (AFSCs) were also introduced to cartilage and bone TE $[8,23,25]$ presenting interesting characteristics, since they are easier to obtain and represent an almost unlimited stem cell sources. Some risks were associated with human AFSCs harvesting but, as pregnant women are older than ever before, amniocentesis is likely to become a routine procedure in future years. More recently, cells from human foetal membranes and placenta, with similar features to human UCMSCs and AFSCs, have also been successfully differentiated into osteogenic and chondrogenic lineages [56]. Although embryonic stem (ES) cells [57] hoped for a promising future in regenerative medicine, their use is still ethically controversial and have major ethical considerations associated. Notwithstanding that human ES cells express molecules which could cause immune rejection [57] and present a high genomic instability [57], ES cell transplantation in a collagen gel has shown to induce the formation of cartilage tissue [17] under mechanical condition in rats aiming at $\mathrm{OC}$ regeneration.

More recently, iPS technology, where iPS cells are generated by reprogramming of somatic cells through the exogenous expression of transcription factors, holds great promise for regenerative medicine in autologous cell replacement therapies and in genetic defects by restoring cellular function [58]. Nevertheless and because of iPS recent development, cell characterization and in vivo functionality are to be addressed in bone and cartilage fields. 
Stem cells obtained from different sources are likely to enable the most successful outcomes in OC regenerative approaches. Besides intrinsic characteristics of stem cells from a particular source, other factors should be monitored aiming at a successful strategy; such as final application, patient age, defect location and damage size. Cell culture media to induce chondrogenesis and osteogenesis of undifferentiated cells or maintain and proliferate primary chondrocytes and osteoblasts in an ex vivo atmosphere are commercially available. However, a common osteochondrocytic medium to co-culture or simultaneously differentiate bone and cartilage cells was not fully established yet, although some attempts have been described $[8,15,59]$. This approach can be advantageous to simplify cell culturing procedures and, simultaneously, reduce the time and production costs of an engineered graft towards a clinical scenario.

\section{Biomaterials: human designs to mimic natural extracellular material}

The implantation of cells in the afflicted area could be a direct approach in OC strategies, but the request for a support material to promote regeneration, especially in large sized defects, is to be critically considered. This idea is inspired in nature itself as, in the body, the majority of cells subsist in a 3D world, anchored onto a network of extracellular matrix (ECM), which scaffolding design proposes to recreate.

Scaffold characteristics will greatly influence cells and should mimic the complex and demanding environment to which cells are exposed to. Besides the tissue structural support and stimulation, either chemically or mechanically, the optimal scaffold should assist tissue functionality promoting the easy diffusion of nutrients, growth factors and cellular waste products [60]. Additionally, the ideal scaffold should be biocompatible and its biodegradability adjustable to the time required for tissue regeneration [60].

In the last few years, thousands of scaffolds have been proposed for reparative strategies made from different materials and production methodologies, with varying properties and composition. An OC scaffold should combine the better of the two worlds in a functional and integrated system. Lots of effort has been undertaken in order to achieve this goal and the most common approach is an independent cartilage or bone strategy, likely because chondrocytes and bone cells present different function-related characteristics including metabolic and structural features, yet communicating and interacting, in a unique culturing system.

Natural based polymers such as agarose [15,61], starch [9], chitosan $[9,13,14,62]$, silk [14], gellan gum [12 $]$, hyaluronic acid [16], collagen [17,63] or blends of these materials $\left[9,14,18,21^{\circ}\right]$, and synthetic materials such as polylactic acid (PLA) [8], polycaprolactone (PCL) [20] and oligo- polyethylene-glycol fumarate [49] have been proposed for cartilage applications. Most of these materials are processed into hydrogel and gel based matrices, which hold particular relevance for cartilage strategies because of their high water content, tissue-like elastic properties and the ability to encapsulate cells [64]. Also, gel structures partially tolerate shock absorption and deformation mimicking articular cartilage characteristics.

However, cartilage repair in OC interfaces should be accompanied by an adequate restoration of the underlying subchondral bone, enhancing the in situ integration of the OC system.

The minerals and the collagen fibres in the matrix are responsible for bone hardness and resistance. Nevertheless, the constant remodelling makes bone very plastic and capable of internal structural changes according to the stresses it is subjected to. Thus, bone regeneration requires scaffolds with high mechanical and osteoconductive properties, and structurally strong enough to sustain weight bearing loads and avoid cartilage calcification, which leads to tissue malfunction and death. Scaffolds should also be biodegradable to keep up with the natural bone remodelling process. Despite the brittle behaviour and low tensile strength, inappropriate for significant torsion areas such as long bones, hydroxyapatite (HA) and tricalcium phosphate (TCP) are the most studied ceramics because of their osteoconductive and high mechanical properties, and are already used in some clinical applications $[4,6]$. Other materials, including silk [2,7], PCL and PCL blends [1,3,5], and PLA [8], have also been effectively tested as delivery systems [2] or artificial ECM [8], mimicking and recreating in some extent the structural organization of bone $[1,3,7]$.

Some OC approaches successfully evaluated the in vivo application of scaffolds made of collagen fibrils with HA nanoparticles without implanted cells [65 $65^{\circ}$, which can be of particular importance if one considers the practical and commercial standpoint, as the engineered product could be a ready-to-use graft for surgery procedures. Furthermore, this approach would avoid tissue morbidity and scarcity of autologous cell sources or even immune reactions from allogenic sources and problems related to cell culturing methodologies (e.g. animal origin supplements).

Other strategies focus on the cellular interactions of implanted cells in the tissue surroundings, considering the reduced metabolism of cartilage. Chondrocytes in adult individuals do not divide or establish cell-to-cell contacts but are responsible to produce cartilage dense ECM [34], thus maintaining cartilage integrity.

Especially in elder patients, implanted cells could meliorate the native ECM properties, and improve the functionality of damaged tissue by stimulating fresh ECM 
Table 1

Overview of the scaffold-cells constructs that have been studied for osteochondral tissue applications in pre-clinical models over the last few years

Scaffolds

OPF with gelatin microparticle hydrogel

PCL/TCP-PCL scaffold

Hyaluronic acid gel sponges

Hyaluronate-type I collagen-fibrin scaffold

Hyaluronic acid-atelocollagen/ $\beta$-TCP bilayered scaffold

Collagen/HA gradient scaffold

Poly(lactide-co-glycolide)/nano-HA scaffold

Polylactic acid (PLA)-coated polyglycolic acid (PGA) scaffold

Collagen $/ \beta$-TCP bilayered scaffold

Cells
Cell-free/marrow mesenchymal stem cells
Cell-free/marrow mesenchymal stromal cells
Autologous mesenchymal stromal cells
Cell-free/autologous chondrocytes
Cell free/chondrocytes
Cell free/autologous chondrocytes
Cell free/marrow mesenchymal stem cells
Cell free/autologous marrow mesenchymal stem cells
Cell free

production. In bony defects, the integration of cells in the implant may stimulate bone marrow cells and establish a metabolic balance favouring the neobone formation. Furthermore, in critical sized defects, cells are likely to participate in a molecular communication level bridging the native tissues to the implant towards a successful OC regeneration.

Different approaches to design an OC scaffold including hydrogels [49], combination of two distinct layers $\left[21^{\bullet}, 29,62,63\right]$ or a gradient scaffold $\left[65^{\bullet}\right]$, usually an association of a gel or a foam and a ceramic, have been developed as alternatives to this problem (Table 1).

These complex scaffolds favour the integration into the native tissue after implantation and guide the cells, into the desired phenotype, according to the prearranged environment created from scaffold physical and chemical properties.

More recently, emerging approaches include the incorporation of bone and/or cartilage growth factors in scaffolds $[49,63]$ to stimulate native tissue formation and differentiation in vivo. The inclusion of growth factors can ultimately recruit host cells into the damaged site, initiating a healing pathway, which could be promising for the treatment of OCDs.

\section{Assisted devices: bioreactor systems}

The limited diffusion in static culture environments may constrain tissue ingrowth in engineered scaffolds. Bioreactors are usually designed to control the transport of nutrients and oxygen to cells in constructs promoting cellular expansion, and in some cases, enabling mechanical stimulation of cultured cells, thus enhancing cell differentiation and ECM formation.

The challenge is, once again, finding a compromise considering the different intrinsic properties of cartilage and bone tissues. In a bioreactor system, dynamic compression should be applied for cartilage ECM stimulation while, for bone, medium perfusion is required to control mass transport and provide shear-stress to stimulate neobone for- mation. To overcome this issue, studies have focused on the development of double chamber bioreactors with physical separation; described to fulfil the needs of tissue-specific mechanical forces for OC stimulation [28,29].

The next step, barely explored, would be the automation of bioreactors controlled by computer software. The customization of engineered grafts through the development of anatomically moulded surfaces [61] has showed potential results headed to translational OC interfaces. As follows bioreactors would be a reliable system of automation and standardization of cell and scaffold methodologies reducing the time and production costs of functional custom-designed grafts.

\section{In vivo models for osteochondral tissue engineering}

Animal studies still represent an essential tool to understand the biologic behaviour of healing and tissue regeneration in vivo, though differences in the anatomy and metabolism of animal models must be considered in an experimental setup with human correlations.

Different animal models have been used in OC studies $\left[16,18-20,21^{\bullet}, 49,51,63,65^{\bullet}\right]$. Rats present distinctive characteristics, such as athymic nude or transgenic animals, not easily available in larger animal models. This model has been used to test the efficacy of a poly(lactideco-glycolide)/nano-HA scaffold seeded with undifferentiated mesenchymal stem cells in OC defects [51]. After 12 weeks, defects treated with these constructs showed smooth and hyaline cartilage with abundant glycosaminoglycan and collagen type II deposition.

Rabbit also demonstrated to be a successful model for OC $[16,20,21,49]$, especially in femoral regions with the successful application of hyaluronate-atelocollagen/betaTCP-hydroxyapatite scaffolds in the patellar grove [21 ${ }^{\circ}$, which promoted, in some extent, OC regeneration without the formation of fibrocartilage.

Sheep is also a popular animal model because of their weight-bearing limbs and with metabolic and bone remo- 
delling rates similar to that of humans as well as the sequence of events in bone graft incorporation and healing capacities. An OC interface was evaluated in sheep by the implantation of a composite scaffold of collagen and HA with or without autologous chondrocytes into a condyle critical defect $\left[65^{\circ}\right]$. Both conditions showed to support neobone formation and hyaline-like cartilage regeneration. With a similar implant, collagen/TCP, OC regeneration was evaluated in the trochlear groove of minipigs [63]. Although cells were absent in this strategy, the in situ incorporation of growth factors in the construct leads to fibrocartilage formation and partial reconstruction of the subchondral bone integrity in a short-term follow-up.

A pilot clinical trial with 13 patients using the collagen/ HA cell free tri-layer scaffold $\left[66^{\circ}\right]$ mentioned above indicated promising results with tissue recovery in some extent after a six-month follow-up.

\section{Conclusions}

The currently available treatments based on 'damage to heal approaches', have a limited success. With an increasing aging population, tissue engineering strategies provide important cues and hope for the treatment of OC degeneration. Ultimately, the tissue engineered implant should be able to stimulate and replace old tissue and native lethargic cells in order to accomplish both regeneration and restoring functions for a successful clinical achievement.

The challenge stands for the replication of the natural functional architecture and the translation of promising strategies towards patient needs. Success lies on the delicate balance of cartilage and bone characteristics combined in an engineered graft, and its integration in vivo. The implant must participate in the regenerative process, considering the specific properties of each OC interface, which can only be achieved through the design of scaffold materials accommodating the specific characteristics of bone and cartilage tissues, and providing stem cells with the necessary cues to satisfy both tissue cellular needs. The application of cells in critical defects or elder patient injuries is likely to be beneficial in stimulating native cells into the regenerative process. The use of bioreactors can improve the functionality of such constructs, accelerate the production, create custom-made systems, and reduce time costs for obtaining implants for OC applications.

\section{Conflict of interest}

Authors declare no conflict of interest.

\section{Acknowledgements}

MT Rodrigues thanks the Portuguese Foundation for Science and Technology (FCT) for providing a PhD scholarship (SFRH/BD/30745/ 2006).

\section{References and recommended reading}

Papers of particular interest, published within the period of review, have been highlighted as:

- of special interest

1. Rodrigues MT, Gomes ME, Viegas CA, Azevedo JT, Dias IR, Guzón $F$, Reis RL: Tissue engineered constructs based on SPCL scaffolds cultured with goat marrow cells: functionality in femoral defects. J Tissue Eng Regen Med 2011, 5:41-49.

2. Bessa PC, Balmayor ER, Hartinger J, Zanoni G, Dopler D, Meinl A, Banerjee A, Casal M, Redl H, Reis RL et al.: Silk fibroin microparticles as carriers for delivery of human recombinant bone morphogenetic protein-2: in vitro and in vivo bioactivity. Tissue Eng Part C Methods 2010, 16:937-945.

3. Gomes ME, Azevedo HS, Moreira AR, Ella V, Kellomaki M, Reis RL: Starch-poly(epsilon-caprolactone) and starch-poly(lactic acid) fibre-mesh scaffolds for bone tissue engineering applications: structure, mechanical properties and degradation behaviour. J Tissue Eng Regen Med 2008, 2:243-252

4. Ogose A, Hotta T, Kawashima H, Kondo N, Gu W, Kamura T, Endo $\mathrm{N}$ : Comparison of hydroxyapatite and beta tricalcium phosphate as bone substitutes after excision of bone tumors. $J$ Biomed Mater Res B Appl Biomater 2005, 72:94-101.

5. Leonor I, Rodrigues MT, Gomes ME, Reis RL: In situ functionalization of wet-spun fibre meshes for bone tissue engineering: one step approach. J Tissue Eng Regen Med 2011 , 5:104-111.

6. Muehrcke DD, Shimp WM, Aponte-Lopez R: Calcium phosphate cements improve bone density when used in osteoporotic sternums. Ann Thorac Surg 2009, 88:1658-1661.

7. Kim HJ, Kim UJ, Kim HS, Li C, Wada M, Leisk GG, Kaplan DL: Bone tissue engineering with premineralized silk scaffolds. Bone 2008, 42:1226-1234.

8. Wang L, Zhao L, Detamore MS: Human umbilical cord mesenchymal stromal cells in a sandwich approach for osteochondral tissue engineering. J Tissue Eng Regen Med 2010 doi: 10.1002/term.370.

9. Sa-Lima H, Caridade SG, Mano JF, Reis RL: Stimuli-responsive chitosan-starch injectable hydrogels combined with encapsulated adipose-derived stromal cells for articular cartilage regeneration. Soft Matter 2010, 6:5184-5195.

10. Oliveira JT, Reis RL: Polysaccharide-based materials for cartilage tissue engineering applications. J Tissue Eng Regen Med 2010 doi: 10.1002/term.335.

11. Maher SA, Mauck RL, Rackwitz L, Tuan RS: A nanofibrous cellseeded hydrogel promotes integration in a cartilage gap model. J Tissue Eng Regen Med 2009, 4:25-29.

12. Oliveira JT, Gardel LS, Rada T, Martins L, Gomes ME, Reis RL: - Injectable gellan gum hydrogels with autologous cells for the treatment of rabbit articular cartilage defects. J Orthop Res 2010, 28:1193-1199.

A very intelligible paper on cartilage engineering, in which several different conditions with gellan gum hydrogels and autologous cells were compared and discussed in a rabbit model.

13. Malafaya PB, Oliveira JT, Reis RL: The effect of insulin-loaded chitosan particle-aggregated scaffolds in chondrogenic differentiation. Tissue Eng Part A 2010, 16:735-747.

14. Silva SS, Motta A, Rodrigues MT, Pinheiro AF, Gomes ME, Mano JF, Reis RL, Migliaresi C: Novel genipin-cross-linked chitosan/silk fibroin sponges for cartilage engineering strategies. Biomacromolecules 2008, 9:2764-2774.

15. Grayson WL, Bhumiratana S, Grace Chao PH, Hung CT, VunjakNovakovic G: Spatial regulation of human mesenchymal stem cell differentiation in engineered osteochondral constructs: effects of pre-differentiation, soluble factors and medium perfusion. Osteoarthritis Cartilage 2010, 18:714-723.

16. Kayakabe M, Tsutsumi S, Watanabe H, Kato $\mathrm{Y}$, Takagishi $\mathrm{K}$ Transplantation of autologous rabbit BM-derived 
mesenchymal stromal cells embedded in hyaluronic acid gel sponge into osteochondral defects of the knee. Cytotherapy 2006, 8:343-353.

17. Nakajima $M$, Wakitani $S$, Harada $Y$, Tanigami $A$, Tomita N: In vivo mechanical condition plays an important role for appearance of cartilage tissue in ES cell transplanted joint. $J$ Orthop Res 2008, 26:10-17.

18. Filova E, Rampichova M, Handl M, Lytvynets A, Halouzka R, Usvald D, Hlucilova J, Prochazka R, Dezortova M, Rolencova E et al.: Composite hyaluronate-type I collagen-fibrin scaffold in the therapy of osteochondral defects in miniature pigs. Physiol Res 2007, 56(Suppl 1):S5-S16.

19. Zhou G, Liu W, Cui L, Wang X, Liu T, Cao Y: Repair of porcine articular osteochondral defects in non-weightbearing areas with autologous bone marrow stromal cells. Tissue Eng 2006, 12:3209-3221.

20. Shao X, Goh JC, Hutmacher DW, Lee EH, Zigang G: Repair of large articular osteochondral defects using hybrid scaffolds and bone marrow-derived mesenchymal stem cells in a rabbit model. Tissue Eng 2006, 12:1539-1551.

21. Ahn JH, Lee TH, Oh JS, Kim SY, Kim HJ, Park IK, Choi BS, Im GI:

- Novel hyaluronate-atelocollagen/beta-TCP-hydroxyapatite biphasic scaffold for the repair of osteochondral defects in rabbits. Tissue Eng Part A 2009, 15:2595-2604.

This study focuses on the fabrication, characterization and in vivo evaluation of a biphasic scaffold, developed to provide cellular subchondra support and avoid collapse in the healing of osteochondral defects.

22. Caplan Al: Adult mesenchymal stem cells for tissue engineering versus regenerative medicine. J Cell Physiol 2007, 213:341-347.

23. De Coppi P, Bartsch G Jr, Siddiqui MM, Xu T, Santos CC, Perin L, Mostoslavsky G, Serre AC, Snyder EY, Yoo JJ et al:: Isolation of amniotic stem cell lines with potential for therapy. Nat Biotechnol 2007, 25:100-106.

24. Fan J, Varshney RR, Ren L, Cai D, Wang DA: Synovium-derived mesenchymal stem cells: a new cell source for musculoskeletal regeneration. Tissue Eng Part B Rev 2009, 15:75-86.

25. Arien-Zakay $\mathrm{H}$, Lazarovici $\mathrm{P}$, Nagler $\mathrm{A}$ : Tissue regeneration potential in human umbilical cord blood. Best Pract Res Clin Haematol 2010, 23:291-303.

26. Rada T, Reis RL, Gomes ME: Adipose tissue-derived stem cells and their application in bone and cartilage tissue engineering Tissue Eng Part B Rev 2009, 15:113-125.

27. Kuroda R, Ishida K, Matsumoto T, Akisue T, Fujioka H, Mizuno K, Ohgushi $\mathrm{H}$, Wakitani S, Kurosaka M: Treatment of a fullthickness articular cartilage defect in the femoral condyle of an athlete with autologous bone-marrow stromal cells. Osteoarthritis Cartilage 2007, 15:226-231.

28. Malafaya PB, Reis RL: Bilayered chitosan-based scaffolds for osteochondral tissue engineering: influence of hydroxyapatite on in vitro cytotoxicity and dynamic bioactivity studies in a specific double-chamber bioreactor. Acta Biomater 2009, 5:644-660.

29. Chang $\mathrm{CH}$, Lin FH, Lin CC, Chou $\mathrm{CH}$, Liu HC: Cartilage tissue engineering on the surface of a novel gelatin-calciumphosphate biphasic scaffold in a double-chamber bioreactor. $J$ Biomed Mater Res B Appl Biomater 2004, 71:313-321.

30. Naran KN, Zoga AC: Osteochondral lesions about the ankle. Radiol Clin North Am 2008, 46:995-1002.

31. Hunter DJ: Risk stratification for knee osteoarthritis progression: a narrative review. Osteoarthritis Cartilage 2009, 17:1402-1407.

32. Li B, Aspden RM: Composition and mechanical properties of cancellous bone from the femoral head of patients with osteoporosis or osteoarthritis. J Bone Miner Res 1997 12:641-651.

33. Sharma L, Kapoor D, Issa S: Epidemiology of osteoarthritis: an update. Curr Opin Rheumatol 2006, 18:147-156.
34. Bhosale AM, Richardson JB: Articular cartilage: structure, injuries and review of management. BrMed Bull 2008, 87:77-95.

35. Kuettner KE, Cole AA: Cartilage degeneration in different human joints. Osteoarthritis Cartilage 2005, 13:93-103.

36. Moyer RF, Birmingham TB, Chesworth BM, Kean CO, Giffin JR: Alignment, body mass and their interaction on dynamic knee joint load in patients with knee osteoarthritis. Osteoarthritis Cartilage 2010, 18:888-893.

37. Peters TA, McLean ID: Osteochondritis dissecans of the patellofemoral joint. Am J Sports Med 2000, 28:63-67.

38. Baker CL 3rd, Romeo AA, Baker CL Jr: Osteochondritis dissecans of the capitellum. Am J Sports Med 2010 doi: 10.1177/0363546509354969.

39. Smith RL, Carter DR, Schurman DJ: Pressure and shear differentially alter human articular chondrocyte metabolism: a review. Clin Orthop Relat Res 2004:S89-S95.

40. Elder BD, Athanasiou KA: Hydrostatic pressure in articular cartilage tissue engineering: from chondrocytes to tissue regeneration. Tissue Eng Part B Rev 2009, 15:43-53.

41. Beris AE, Lykissas MG, Papageorgiou CD, Georgoulis AD: Advances in articular cartilage repair. Injury 2005, 36(Suppl 4):S14-23.

42. Lattermann C, Romine SE: Osteochondral allografts: state of the art. Clin Sports Med 2009, 28:285-301.

43. Gross AE, Shasha N, Aubin P: Long-term followup of the use of fresh osteochondral allografts for posttraumatic knee defects. Clin Orthop Relat Res 2005:79-87.

44. Gikas PD, Bayliss L, Bentley G, Briggs TW: An overview of autologous chondrocyte implantation. $J$ Bone Joint Surg $B r$ 2009, 91:997-1006.

45. Peterson L, Brittberg M, Kiviranta I, Akerlund EL, Lindahl A: Autologous chondrocyte transplantation. Biomechanics and long-term durability. Am J Sports Med 2002, 30:2-12.

46. Hangody L, Vasarhelyi G, Hangody LR, Sukosd Z, Tibay G, Bartha L, Bodo G: Autologous osteochondral grafting technique and long-term results. Injury 2008, 39(Suppl 1): S32-39.

47. Ulutas K, Menderes A, Karaca C, Ozkal S: Repair of cartilage defects with periosteal grafts. Br J Plast Surg 2005, 58:65-72.

48. Niemeyer P, Fechner K, Milz S, Richter W, Suedkamp NP, Mehlhorn AT, Pearce S, Kasten P: Comparison of mesenchymal stem cells from bone marrow and adipose tissue for bone regeneration in a critical size defect of the sheep tibia and the influence of platelet-rich plasma. Biomaterials 2010, 31:3572-3579.

49. Guo X, Park H, Young S, Kretlow JD, van den Beucken JJ, Baggett LS, Tabata Y, Kasper FK, Mikos AG, Jansen JA: Repair of osteochondral defects with biodegradable hydrogel composites encapsulating marrow mesenchymal stem cells in a rabbit model. Acta Biomater 2010, 6:39-47.

50. Im GI, Shin YW, Lee KB: Do adipose tissue-derived mesenchymal stem cells have the same osteogenic and chondrogenic potential as bone marrow-derived cells? Osteoarthritis Cartilage 2005, 13:845-853.

51. Xue D, Zheng Q, Zong C, Li Q, Li H, Qian S, Zhang B, Yu L, Pan Z: Osteochondral repair using porous poly(lactide-co-glycolide)/ nano-hydroxyapatite hybrid scaffolds with undifferentiated mesenchymal stem cells in a rat model. J Biomed Mater Res A 2010, 94:259-270.

52. Mizuno $\mathrm{H}$ : Adipose-derived stem cells for tissue repair and regeneration: ten years of research and a literature review. $J$ Nippon Med Sch 2009, 76:56-66.

53. Wakitani S, Mitsuoka T, Nakamura N, Toritsuka Y, Nakamura $Y$, Horibe S: Autologous bone marrow stromal cell transplantation for repair of full-thickness articular cartilage defects in human patellae: two case reports. Cell Transplant 2004, 13:595-600. 
8 Tissue, cell and pathway engineering

54. Ringe J, Leinhase I, Stich S, Loch A, Neumann K, Haisch A, Haupl T, Manz R, Kaps C, Sittinger M: Human mastoid periosteum-derived stem cells: promising candidates for skeletal tissue engineering. J Tissue Eng Regen Med 2008, 2:136-146.

55. Jansen EJ, Emans PJ, Guldemond NA, van Rhijn LW, Welting TJ Bulstra SK, Kuijer R: Human periosteum-derived cells from elderly patients as a source for cartilage tissue engineering? J Tissue Eng Regen Med 2008, 2:331-339.

56. Soncini M, Vertua E, Gibelli L, Zorzi F, Denegri M, Albertini A, Wengler GS, Parolini O: Isolation and characterization of mesenchymal cells from human fetal membranes. J Tissue Eng Regen Med 2007, 1:296-305.

57. Stojkovic M, Lako M, Strachan T, Murdoch A: Derivation, growth and applications of human embryonic stem cells. Reproduction 2004, 128:259-267.

58. Kiskinis E, Eggan K: Progress toward the clinical application of patient-specific pluripotent stem cells. J Clin Invest 2010, 120:51-59.

59. Li J, Mareddy S, Tan DM, Crawford R, Long X, Miao X, Xiao Y: A minimal common osteochondrocytic differentiation medium for the osteogenic and chondrogenic differentiation of bone marrow stromal cells in the construction of osteochondral graft. Tissue Eng Part A 2009, 15:2481-2490.

60. Hutmacher DW, Schantz JT, Lam CX, Tan KC, Lim TC: State of the art and future directions of scaffold-based bone engineering from a biomaterials perspective. J Tissue Eng Regen Med 2007, 1:245-260.

61. Hung CT, Lima EG, Mauck RL, Takai E, LeRoux MA, Lu HH, Stark RG, Guo XE, Ateshian GA: Anatomically shaped osteochondral constructs for articular cartilage repair. J Biomech 2003, 36:1853-1864.

62. Oliveira JM, Rodrigues MT, Silva SS, Malafaya PB, Gomes ME, Viegas CA, Dias IR, Azevedo JT, Mano JF, Reis RL: Novel hydroxyapatite/chitosan bilayered scaffold for osteochondral tissue-engineering applications: scaffold design and its performance when seeded with goat bone marrow stromal cells. Biomaterials 2006, 27:6123-6137.

63. Gotterbarm T, Richter W, Jung M, Berardi Vilei S, Mainil-Varlet P Yamashita T, Breusch SJ: An in vivo study of a growth-factor enhanced, cell free, two-layered collagen-tricalcium phosphate in deep osteochondral defects. Biomaterials 2006 , 27:3387-3395.

64. Nicodemus GD, Bryant SJ: Cell encapsulation in biodegradable hydrogels for tissue engineering applications. Tissue Eng Part $B$ Rev 2008, 14:149-165.

65. Kon E, Delcogliano M, Filardo G, Fini M, Giavaresi G, Francioli S,

- Martin I, Pressato D, Arcangeli E, Quarto R et al:: Orderly osteochondral regeneration in a sheep model using a nove nano-composite multilayered biomaterial. J Orthop Res 2010, 28:116-124.

A very interesting approach to the complexity of osteochondral interface in regenerative strategies.

66. Kon E, Delcogliano M, Filardo G, Pressato D, Busacca M,

- Grigolo B, Desando G, Marcacci M: A novel nano-composite multi-layered biomaterial for treatment of osteochondral lesions: technique note and an early stability pilot clinical trial. Injury 2010, 41:693-701.

A pioneer study aiming at osteochondral regeneration in human patients. 